\title{
Monoclonal Antibodies for Multiple Sclerosis Treatment
}

\author{
Anticorpos Monoclonais para Tratamento da Esclerose Múltipla
}

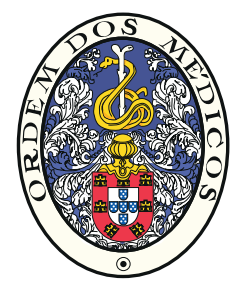

Filipe PALAVRA $\triangle^{1,2}$

Acta Med Port 2015 Sep-Oct;28(5):640-651

ABSTRACT

Since their introduction in medical therapy, in the last quarter of the $20^{\text {th }}$ century, monoclonal antibodies have gained an increasing importance in the treatment of various diseases. Neurology has been one of the medical specialties benefiting of the therapeutic potential of these monoclonal antibodies and certain neurological conditions may now contain such drugs in their therapeutic algorithms. Multiple sclerosis is one of these diseases and, in addition to the monoclonal antibodies already licensed for clinical use, several others are in development for future utilization in this specific area. The future will certainly pass through this kind of drugs and, in this article, a review of the most relevant data related to monoclonal antibodies already in use and also in clinical development for multiple sclerosis treatment will be performed.

Keywords: Antibodies, Monoclonal; Clinical Trials; Multiple Sclerosis.

\section{RESUMO}

Desde a sua introdução na terapêutica médica, no último quarto do século $X X$, os anticorpos monoclonais têm ganho cada vez mais importância no tratamento de várias doenças. A Neurologia tem sido uma das especialidades médicas a beneficiar do potencial terapêutico destes anticorpos monoclonais e algumas doenças neurológicas podem já contar com fármacos deste tipo nos seus algoritmos terapêuticos. A esclerose múltipla é uma dessas doenças e, para além dos já licenciados para utilização clínica, são vários os anticorpos monoclonais que se encontram em desenvolvimento para futura utilização nesta área específica. O futuro passará certamente por fármacos deste tipo e, neste artigo, far-se-á uma revisão dos dados mais relevantes relacionados com os anticorpos monoclonais já em uso e também em desenvolvimento clínico para tratamento da esclerose múltipla.

Palavras-chave: Anticorpos Monoclonais; Ensaios Clínicos; Esclerose Múltipla.

\section{INTRODUCTION}

At the end of the $19^{\text {th }}$ century, Kitasato and Behring performed a set of experiments that led to the demonstration that immunologically naïve animals could be protected by serum taken from animals treated with nonlethal doses of diphtheria and tetanus preparations. ${ }^{1}$ These experiments established the basis for serum therapy and opened up avenues of research that, throughout the $20^{\text {th }}$ century, with the development of multiple vaccines, dramatically changed the epidemiology of many (until then) common diseases causing high mortality rates. In 1975, Kohler and Milstein developed a procedure for the production of mouse monoclonal antibodies (mAbs) that ensured a constant generation of specific and pure antibodies. ${ }^{2}$ This method opened a new chapter in modern Immunology and allowed to start considering mAbs as valuable therapeutic agents in diverse clinical settings.

Neurology is one of the medical disciplines currently taking advantage from this knowledge and there are already some neurological conditions that can now be treated with mAbs. Multiple sclerosis (MS) is one of those conditions and, in addition to the drugs already available in the market, there is a fruitful research pipeline, which includes some mAbs that, in the short and medium run, can be available for clinical usage (Table 1 contains a summary of the profile of the drugs which will be presented and Table 2 the most relevant data from clinical trials that will be focused). Specificities of these drugs require clinicians to have clearly in mind the safety and efficacy data supporting their practical use. In this paper we will make a revision about currently approved and still under investigation mAbs for MS treatment.

\section{Natalizumab}

The inflammatory process that produces demyelination and axonal loss in patients diagnosed with relapsing forms of MS is closely linked to the infiltration of central nervous system (CNS) by leukocytes. ${ }^{3}$ The accumulation of lymphocytes and monocytes into the CNS is a very complex process that affects molecular factors promoting migration through the blood-brain-barrier (BBB) and facilitating proliferation and survival of leukocytes inside the CNS. For migration across the BBB, expression of activated adhesion molecules on leukocyte surface is required. One of these molecules is the integrin $\alpha 4 \beta 1$, a glycoprotein that is expressed on the surface of lymphocytes, monocytes, mast cells, macrophages, basophils and eosinophils (but not in neutrophils). ${ }^{4} \mathrm{An}$ important ligand of the integrin $\alpha 4 \beta 1$ is the vascular cell adhesion molecule 1 (VCAM-1), which is

\footnotetext{
1. Institute for Biomedical Imaging and Life Sciences, CNC. IBILI Research Unit. Faculdade de Medicina. Universidade de Coimbra. Coimbra. Portugal.

2. Institute for Nuclear Sciences Applied to Health (ICNAS). Faculdade de Medicina. Universidade de Coimbra. Coimbra. Portugal.

$\triangle$ Autor correspondente: Filipe Palavra. fpalavra@fmed.uc.pt

Recebido: 07 de Abril de 2015 - Aceite: 14 de Julho de 2015 | Copyright @ Ordem dos Médicos 2015
} 
Table 1 - Summary of the principal data related with the profile of mAbs already in use and under investigation for MS treatment

\begin{tabular}{llll}
\hline Name & Type & Target & Phase of development \\
\hline Natalizumab & Humanized & CD49d & Already used in clinical practice (phase IV) \\
Alemtuzumab & Humanized & CD52 & Phase III program completed \\
Aaclizumab & Humanized & CD25 & Phase III \\
Ocrelizumab & Humanized & CD20 & Phase III \\
Ofatumumab & Fully human & CD20 & Phase II \\
GNbAC1 & Humanized & MSRV-ENV & Phase II \\
BIIB033 & Fully human & LINGO-1 & Phase II \\
MOR103 & Fully human & GM-CSF & Phase I \\
MEDI-551 & Humanized & CD19 & Phase I/II
\end{tabular}

EMA: European Medicines Agency; FDA: United States Food and Drug Administration; MSRV-ENV: Multiple sclerosis-associated retrovirus-ENV protein; LINGO-1: Leucine-rich repeat and Ig domain containing NOGO receptor interacting protein 1; GM-CSF: Granulocyte-macrophage colony-stimulating factor.

expressed on the surface of vascular endothelial cells. It was demonstrated that integrin $\alpha 4 \beta 1$ and VCAM-1 expression is increased in chronic MS plaques and that, under the control of pro-inflammatory cytokines, integrin $\alpha 4 \beta 1$ activation and interaction with VCAM-1 are crucial for activated monocytes and lymphocytes to adhere to vascular wall and to migrate into inflamed areas of the CNS. ${ }^{5}$

Natalizumab (Tysabri ${ }^{\circledR}$; Biogen Elan Pharmaceuticals) is a humanized antibody directed against the integrin a4-subunit (CD49d), derived from a murine monoclonal antibody (mAb) anti-human integrin $\alpha 4 \beta 1$. It was the first drug in a new class of selective adhesion molecule inhibitors, which completely revolutionized the treatment of relapsing-remitting MS (RRMS). ${ }^{6}$

The efficacy of the drug in the treatment of adult patients diagnosed with RRMS is supported by data coming from two fully published, large, randomized, double-blind, multicentre, phase III trials: the AFFIRM (Natalizumab Safety and Efficacy in Relapsing Remitting Multiple Sclerosis) ${ }^{7}$ and the SENTINEL (Safety and Efficacy of Natalizumab in Combination with Interferon Beta-1a in Patients with Relapsing Remitting Multiple Sclerosis) ${ }^{8}$ trials.

In the AFFIRM study (NCT00027300), the efficacy of natalizumab monotherapy (intravenous $300 \mathrm{mg}$ every four weeks) was compared with placebo for two years in RRMS patients aged 18 - 50 years $(n=942)$. Natalizumab-treated patients showed a significant $(p<0.001)$ reduction in the risk of sustained disability progression by $42 \%$ compared to those randomized to placebo at two years and also experienced a significant $(p<0.001)$ reduction in the annualized relapse rate by $68 \%$ at one year. This reduction was maintained at two years and the proportions of patients free of relapse were significantly $(p<0.001)$ higher with natalizumab than with placebo at the end of both years. ${ }^{7}$ Also from the magnetic resonance imaging (MRI) point of view the results obtained with the mAb were superior, compared with placebo. Natalizumab significantly $(p<0.001)$ reduced the number of new or enlarging hyperintense lesions on T2weighted images by $80 \%$ at one year and by $83 \%$ at two years. It also reduced the number of gadolinium-enhancing lesions by $92 \%$ at both one and two years, compared with placebo $(p<0.001)$ and, in addition, natalizumab reduced the number of new T1-hypointense lesions by $74 \%$ at one year and by $83 \%$ at two years, compared with placebo $(p<$ $0.001){ }^{7}$

The SENTINEL study (NCT00030966) compared the addition of natalizumab (also given in the dose of $300 \mathrm{mg}$ intravenously every four weeks) versus placebo to existing interferon beta-1a therapy (30 $\mu \mathrm{g}$ intramuscularly once a week) in RRMS patients aged 18 - 55 years $(n=1171)$. The combination of natalizumab with interferon beta-1a significantly $(p=0.02)$ reduced the risk of sustained disability progression at two years by $24 \%$ compared with the addition of placebo to interferon and also reduced the annualized relapse rate by $54 \%$ at one year $(p<0.001)$, which was also maintained at the end of the trial. ${ }^{8}$ Considering the MRI outcomes, combination therapy reduced the number of new or enlarging T2-hyperintense lesions by $83 \%$ and the number of gadolinium-enhancing lesions by $89 \%$ over 2 years compared with interferon beta-1a alone $(p<0.001) .{ }^{8}$

Both trials demonstrated that the general tolerability profile of natalizumab was good, but the SENTINEL study placed neurologists for the first time in contact with the major problem associated with the administration of this 


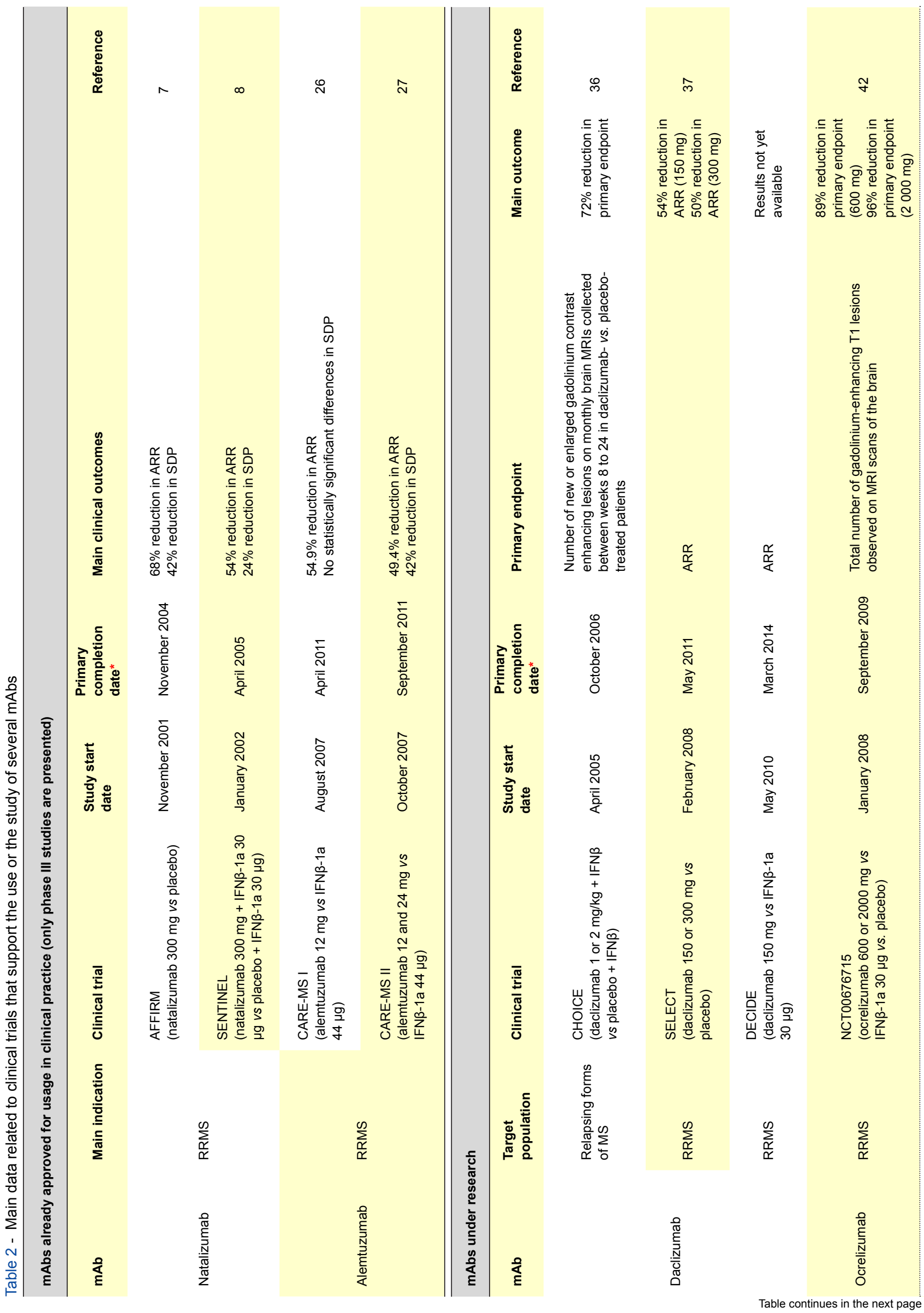




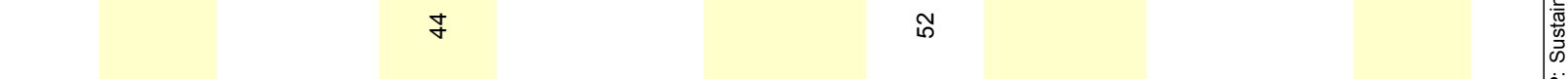

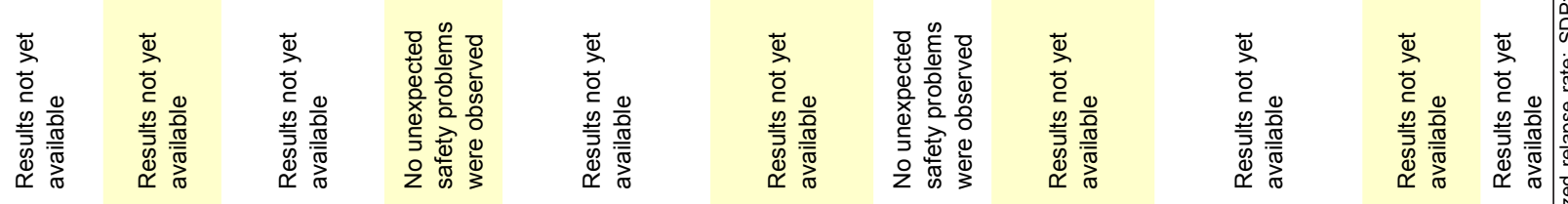
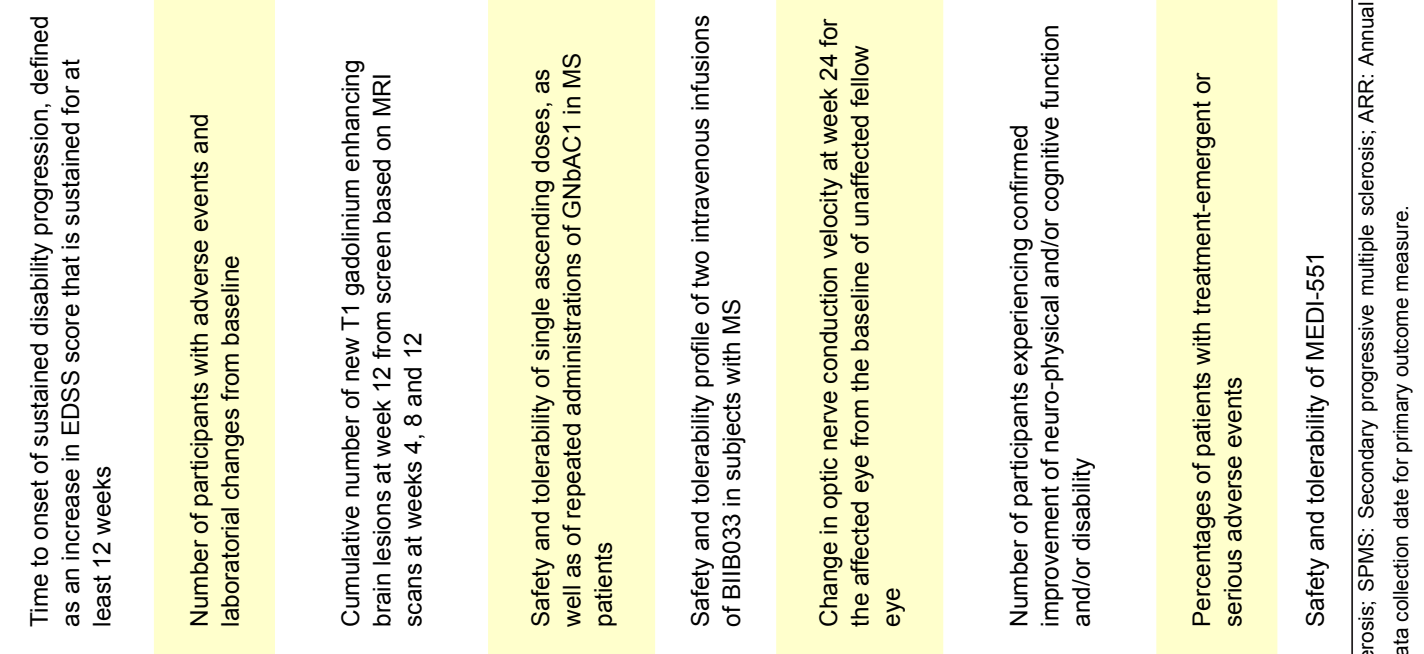

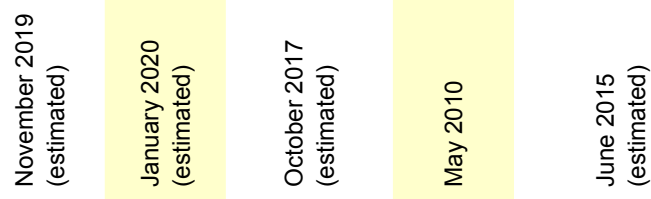

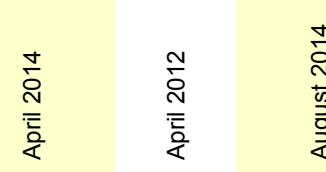

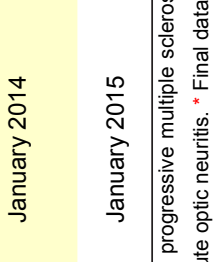

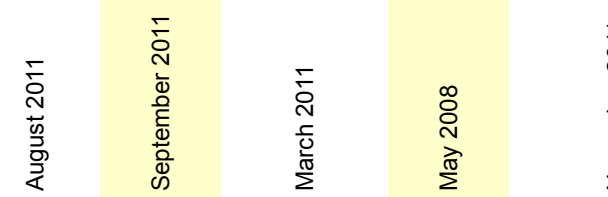

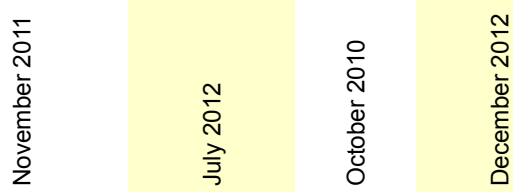

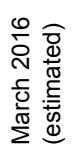

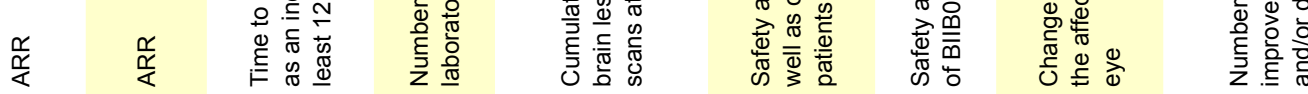

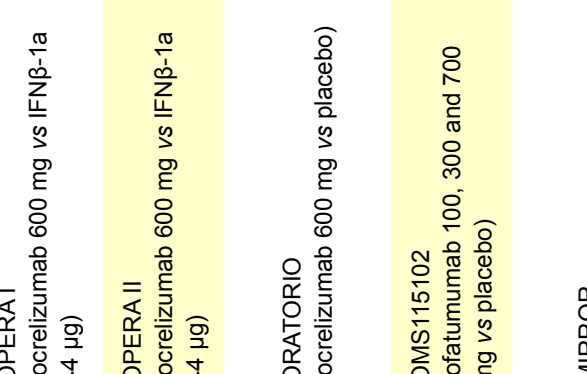

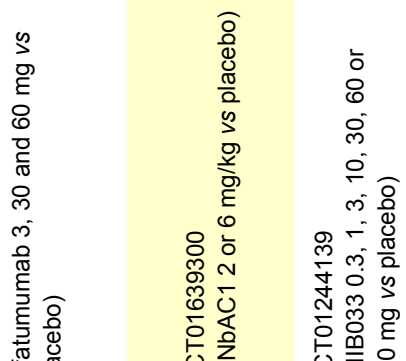

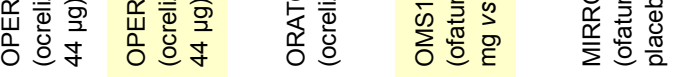

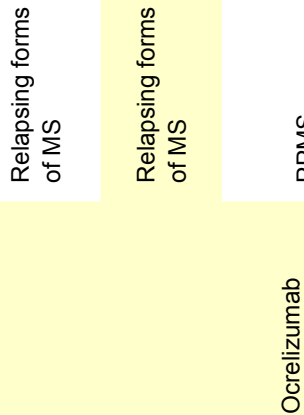
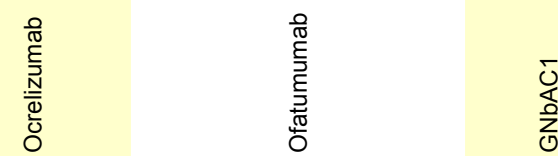

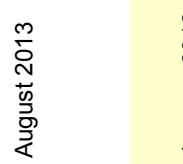

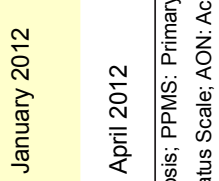

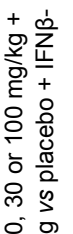

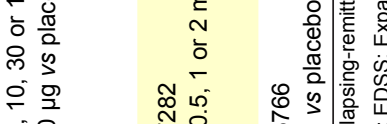

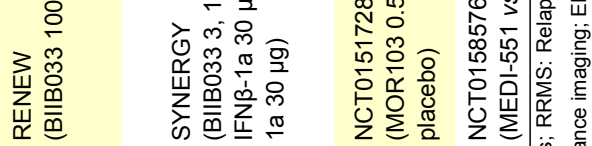

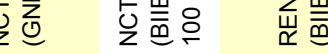

$\stackrel{0}{5}$
$\frac{0}{0}$
$\frac{0}{0}$
$\frac{0}{0}$
$\frac{\pi}{0}$
$\square$

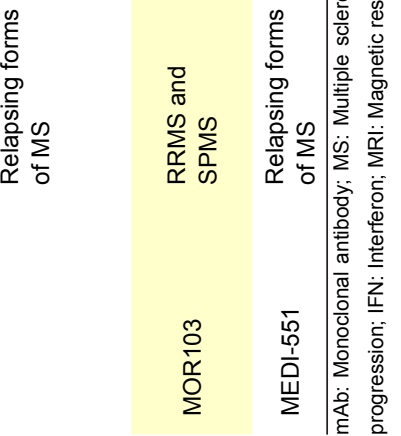


mAb, which turned out to be responsible for the approval of its clinical usage only in monotherapy: the incidence of progressive multifocal leukoencephalopathy (PML). PML is caused by opportunistic infection of the CNS with the human polyomavirus JC virus, probably as a result of impaired immune surveillance following the inhibition of leukocyte migration across the BBB by natalizumab and/or the depletion of antigen presenting cells. ${ }^{9,10}$ The virus infects glial cells in the brain, leading to lysis of oligodendrocytes, which defines the underlying pathology and results in rapid demyelination affecting predominantly the subcortical white matter. ${ }^{9}$ According to the manufacturer's data cited on a multiple sclerosis research website, as of $3^{\text {rd }}$ December 2014 , there have been 517 confirmed cases of PML among nearly 132600 natalizumab-treated MS patients, producing a risk of nearly 3.9 cases per 1000 patients receiving the drug. ${ }^{11}$ The risk factors associated with PML appear to be longer duration of natalizumab treatment (particularly beyond two years), prior exposure to the effect of immunosuppressive drugs and positivity for anti-JC virus antibodies. In addition to this, titres of these antibodies (measured as an index) may also play a role in risk stratification and their inclusion in the algorithm may help to optimize the clinical approach to the problem. ${ }^{12}$ The estimated incidence of $\mathrm{PML}$ in patients presenting all the risk factors is of about 11.2 cases per 1000 patients, compared with an estimated incidence of 0.1 cases per 1000 patients in the lowest risk group (defined by those with a negative result for anti-JC virus antibody). ${ }^{11}$ Thus, testing for JC virus antibodies prior to starting natalizumab therapy and testing every 6 months thereafter is considered prudent practice, in order to better stratify the risk of the patient to develop PML. ${ }^{13}$

This constant and dynamic process of risk assessment exposes another very critical aspect of natalizumab usage in clinical practice: how to continue immunotherapy after drug cessation. After natalizumab withdrawal, previous disease activity may return, ${ }^{14}$ but the timing of this return is quite variable and optimal monitoring and treatment strategies for patients discontinuing natalizumab are not currently established and still rely on MS centres empirical experience. In order to answer some of these questions, the RESTORE trial (NCT01071083) was designed (it was a randomized, partially placebo-controlled study aiming to explore the course of disease activity and the effects on immune, pharmacokinetic and pharmacodynamic aspects in patients undergoing an interruption of natalizumab administration for up to 24 weeks, comparing to those who remained on treatment with the $\mathrm{mAb}){ }^{15}$ To be relapsefree through the prior year on natalizumab and have no gadolinium-enhancing lesions on screening brain MRI were the main inclusion criteria for patients to be eligible for the study. They were randomized to continue on natalizumab, to switch to placebo or to receive other immunomodulatory drugs, such as intramuscular interferon beta-1a, subcutaneous glatiramer acetate or intravenous methylprednisolone, entering thereafter in a regular clinical and MRI assessment protocol. None $(0 \%)$ of the patients randomized to receive intravenous natalizumab showed MRI activity recurrence, compared with $46 \%$ of the patients taking placebo, $7 \%$ of those receiving interferon beta$1 \mathrm{a}, 53 \%$ of those under glatiramer acetate and $40 \%$ in the methylprednisolone arm. Relapses occurred in $4 \%$ of the natalizumab-treated patients and in $15-29 \%$ of those receiving other treatments, being reported as early as 4-8 weeks after last natalizumab bolus administration. Overall, in this study, $30 \%$ of the patients restarted treatment with natalizumab because of disease activity. ${ }^{15}$

Having these results, switching patients to fingolimod instead of a less effective first-line agent after a natalizumab washout period might be considered as a reasonable therapeutic option. However, a number of publications reported disease reactivation in a proportion of patients after a switch from natalizumab to fingolimod and this strategy needs yet to be further explored in large clinical trials. ${ }^{16-18}$

Nevertheless, on the basis of current evidence, natalizumab is a proven effective treatment for reducing MS disease activity and severity. However, despite this strong evidence for the efficacy of the drug, the risk of PML will probably limit the use of this agent early in disease course, especially if (and when) safer options become available on the market.

\section{Alemtuzumab}

Alemtuzumab (Lemtrada ${ }^{\circledR} ;$ Genzyme, Sanofi) is a humanized $\mathrm{mAb}$ directed against the CD52 antigen, which is a membrane glycoprotein expressed on $T$ and $B$ lymphocytes, natural killer (NK) cells, macrophages and monocytes, dendritic cells and the majority of granulocytes (excluding the neutrophils). ${ }^{19}$ The high density of CD52 expression on the cellular surface (mainly on lymphocytes) makes it a good target for antibody-mediated cytotoxicity and complement-mediated lysis, promoting a sustained drug-induced cellular depletion. However, that does not affect haematological progenitors.

This antibody was firstly used in patients with MS in 1991 with the hope that the T-cell repertoire regenerated after lymphocyte depletion by the drug would no longer exert the aberrant responses characteristic of MS. ${ }^{20}$ The results of these initial studies were published in 1999 and then in 2006. ${ }^{21-23}$ The investigators concluded that patients who benefited most from the therapeutic effect of alemtuzumab were those with an inflammatory phenotype (more than those with progressive MS), ${ }^{22}$ particularly in the early stages of the disease. Having this, they proposed the concept of a 'window of therapeutic opportunity' using alemtuzumab ${ }^{23}$ and these aspects were crucial to the definition of the inclusion criteria in the phase II clinical trial CAMMS223 (NCT00050778), which was further planned. ${ }^{24}$

In this phase II rater-blinded trial 334 RRMS patients were randomized to receive cycles of intravenous alemtuzumab or subcutaneous interferon beta-1a $\left(\operatorname{Rebi}^{\circledR}\right), 44 \mu \mathrm{g}$ three times per week). Alemtuzumab was given at two different daily doses (12 or $24 \mathrm{mg}$, administered for five consecutive days in the first month and for three consecutive days in the 
months 12 and 24), giving three treatment groups in total. Compared to interferon beta-1a, alemtuzumab significantly reduced the risk of sustained disability, as measured by the EDSS (Expanded Disability Status Scale) ${ }^{25}$ score by $71 \%(p<0.001)$ and decreased the relapse rate by $74 \%$ more than interferon $(p<0.001)$. After 36 months, $80 \%$ of patients taking alemtuzumab and $52 \%$ of those treated with interferon beta-1a remained relapse-free. ${ }^{24}$ These positive results reinforced the interest in pushing forward drug's clinical development program and two phase III studies were then conducted: CARE-MS I and CARE-MS II.

The CARE-MS I trial (Comparison of Alemtuzumab and Rebif ${ }^{\circledR}$ Efficacy in Multiple Sclerosis, Study One, NCT00530348) was a 2-year randomized and controlled study designed to investigate the efficacy and safety of firstline treatment with alemtuzumab (only in the dosage of 12 $\mathrm{mg} /$ day) in comparison to subcutaneous interferon beta-1a (44 $\mu \mathrm{g}$ three times per week) in 581 included, therapy-naïve patients with RRMS. ${ }^{26}$ All these patients had a disease duration of no more than five years, were fully ambulatory (EDSS score $\leq 3.0$ ) and all had at least two relapses in the previous two years, with at least one relapse during the last year. Patients and treating physicians were not blinded to treatment, but EDSS and MRI assessments were performed in a blinded manner. Considering the results of the trial, while $40 \%$ of the patients treated with interferon beta-1a experienced a relapse over two years, only $22 \%$ of the alemtuzumab-treated ones did so and this represented a significant reduction of $54.9 \%$ in the annualized relapse rate $(p<0.001)$. However, this was the only coprimary endpoint that was met, because it was not possible to demonstrate a significant reduction in disability progression: $8 \%$ of the patients randomized to receive alemtuzumab showed 6-month confirmed EDSS progression versus $11 \%$ of those treated with interferon beta-1a $(p=0.22)$. Among secondary endpoints and considering mainly data coming from MRI assessments, alemtuzumab significantly reduced the proportion of patients with gadolinium-enhancing lesions in comparison to interferon beta-1a $(p<0.0001)$ and slowed brain volume loss by approximately $40 \%$ ( $p<$ $0.0001)$. Despite all the methodological limitations of this - according to current standards - small phase III clinical trial, the truth is that data obtained were not so strong as those generated by the CAMMS223 study, raising some doubts about the adequacy of the treatment with this mAb in patients with early and treatment-naïve RRMS. However, for patients with breakthrough disease despite treatment with first-line immunomodulators alemtuzumab could be a relevant option. And to clarify this clinical question a new trial was designed: the CARE-MS II.

The CARE-MS II study (Comparison of Alemtuzumab and Rebif $^{\circledR}$ Efficacy in Multiple Sclerosis, Study Two, NCT00548405) was also a 2-year randomised and controlled trial, largely rater-masked, aiming to investigate the efficacy and safety of alemtuzumab using the same active comparator (subcutaneous interferon beta-1a, $44 \mu \mathrm{g}$ three times per week) in patients who had a breakthrough disease on another immunotherapy (different interferon beta preparations, glatiramer acetate and natalizumab). ${ }^{27}$ The population of patients included 840 individuals with a disease duration of no more than 10 years, an EDSS score $\leq 5.0$ and with at least two relapses in the previous two years with at least one relapse during the last year. Overall, this cohort included moderately disabled patients with active, still rather early RRMS who had failed on another disease-modifying therapy. In this trial the mAb was administered initially in two different dosages (12 and $24 \mathrm{mg} /$ day), but a further protocol amendment suppressed the 24-mg group to increase the number of patients in the two remaining groups. Again, relapse rate and time to 6-month sustained disability progression were considered as coprimary endpoints and in this trial both were met. Patients treated with alemtuzumab experienced a reduction of $49.4 \%$ in the annualized relapse rate $(p<0.0001)$ and they also had a $42 \%(p=0.0084)$ relative risk reduction of sustained worsening of disability after two years. Regarding secondary endpoints, alemtuzumab significantly reduced the proportion of patients with gadolinium-enhancing lesions in MRI comparing to interferon beta-1a $(p<0.0001)$, it decreased the number o patients with new or enlarging T2-hyperintense lesions $(p<0.0001)$ and significantly reduced brain volume loss $(p=0.01)$.

Data provided by the CARE-MS II trial seem to help in clarifying the profile of patients benefiting most of this treatment. However, safety and tolerability issues were raised in all these studies and need also to be highlighted. Acute infusion reactions (headache, rash, fever and nausea) were recorded in $90 \%$ of patients receiving alemtuzumab, but their frequency decreased in subsequent infusions of the drug. Nasopharyngitis, respiratory and urinary tract infections as well as herpes infections were more frequently observed in patients taking alemtuzumab than in those receiving interferon beta-1a. Both CARE-MS I and II raised the issue of autoimmune adverse events: $18 \%$ of alemtuzumab-treated patients in CARE-MS I and $16 \%$ in CARE-MS II developed autoimmune thyroid disorders, 1\% developed immune thrombocytopenia requiring treatment, one patient developed glomerulonephritis with elevated anti-glomerular basement membrane antibodies during safety follow-up and another patient was diagnosed with presumed autoimmune pancytopenia 19 months after his last alemtuzumab course..$^{26,27}$

Although not fulfilling all the high expectations derived from CAMMS223, results from CARE-MS I and II are nevertheless encouraging. Alemtuzumab's convenience of administration and significant effects on relapse frequency and disability accumulation made it a very interesting drug, despite the high frequency of potentially serious, but treatable, side effects. Having this, the European regulatory agency approved and has granted marketing authorization for alemtuzumab, under the commercial name of Lemtrada ${ }^{\circledR}, 12 \mathrm{mg}$ concentrate for solution for infusion. Its therapeutic indications were restricted to 'adult patients with relapsing remitting multiple sclerosis (RRMS) with 
active disease defined by clinical or imaging features' ${ }^{28}$ The American Food and Drug Administration (FDA) took more time to approve the use of the drug in clinical practice, but this actually happened in November 2014.

There are future developments that could improve patients' access to the drug: first of all, a robust predictive biomarker of autoimmunity following treatment with this mAb (IL-21 is being studied as a possible marker to individualize risks for patient counselling before treatment and to establish the intensity of monitoring after drug administration) ${ }^{29}$ and/or a method for reducing the risk of autoimmune adverse events (there is a current trial using alemtuzumab combined with palifermin, a drug that promotes thymic T cell regeneration - NCT01712945 exploring and testing this possibility).

\section{Daclizumab}

Daclizumab (Biogen and Abbott Biotherapeutics Corp.) is a humanized mAb acting as a blocker of the $\alpha$-subunit (CD25) of the high-affinity IL-2 receptor. ${ }^{19}$ IL-2 is secreted by activated lymphocytes and stimulates production of other proinflammatory cytokines while it is also involved in lymphocytic proliferation. Daclizumab was initially approved for the prevention of renal allograft rejection as part of a combination regimen and evidence was progressively accumulated showing that this drug could also be effective in other diseases, such as non-infectious uveitis ${ }^{30,31}$ and MS. ${ }^{32-38}$

After demonstrating that the drug could be effective in animal models of the disease, 10 patients diagnosed with RRMS and secondary progressive MS (SPMS) were treated for six months with the combination of intravenous daclizumab (at $1 \mathrm{mg} / \mathrm{kg} / \mathrm{dose}$ two weeks apart for the first two doses and once every four weeks thereafter for a total of seven infusions) and interferon beta after suboptimal response to the latter alone. ${ }^{32}$ In this study it was possible to demonstrate that patients undergoing this combination therapy experienced a $78 \%$ reduction in new contrastenhancing lesions, as compared to the baseline moment $(p=0.004)$ and a significant improvement in some clinical outcome measures, such as the relapse rate (a reduction of $80.7 \% ; p=0.047$ ). Three more small studies were thereafter published, either comparing daclizumab in combination with interferon beta or in monotherapy in RRMS and SPMS patients. ${ }^{33-35}$

In order to obtain more robust data, with a larger population of patients, the CHOICE study (Study of Subcutaneous Daclizumab in Patients With Active, Relapsing Forms of Multiple Sclerosis, NCT00109161) was designed and the results were published in 2010. ${ }^{36}$ This was a phase II, randomised, double-blind and placebocontrolled study that recruited 230 patients with relapsing forms of MS who were taking interferon beta for at least six months and, despite of this therapy, presented active diseases. They were then randomized to receive add-on subcutaneous daclizumab in two different doses $(2 \mathrm{mg} / \mathrm{kg}$ every two weeks and $1 \mathrm{mg} / \mathrm{kg}$ every four weeks) or placebo for 24 weeks. The primary endpoint was the total number of new or enlarged gadolinium-enhancing lesions identified on brain MRI performed every four weeks between weeks 8 and 24. At the end of the study and only for those patients receiving interferon beta plus the highest dose of daclizumab a significant difference in the primary endpoint was found, comparing with those receiving interferon beta and placebo $(72 \%$ reduction; $p=0.004)$. The study was not powered to demonstrate clinical efficacy.

The SELECT trial (Safety and Efficacy Study of Daclizumab High Yield Process to Treat RelapsingRemitting Multiple Sclerosis, NCT00390221) was a 1-year, double-blind, phase Ilb study investigating two doses of subcutaneous daclizumab used in monotherapy (150 and $300 \mathrm{mg}$ ) compared with placebo in 600 RRMS randomised patients. ${ }^{37}$ In this trial, a slightly different formulation of daclizumab (High Yield Process [HYP]) was used: it has the same aminoacid sequence as previous versions of the mAb, but it differs in its glycosylation profile, decreasing antibodydependent cytotoxicity. At baseline, patients had an EDSS score $\leq 5.0$ and at least one relapse in the previous year or an MRI scan showing pathological gadolinium enhancement within six weeks prior to randomization. Annualized relapse rate was defined as the primary endpoint and it was met as nearly all the secondary endpoints. Compared with patients receiving placebo, those treated with $150 \mathrm{mg}$ of daclizumab experienced a reduction of $54 \%$ in relapse rate $(p<$ 0.0001 ) and those receiving $300 \mathrm{mg}$ had a $50 \%$ reduction $(p=0.0002)$. The number of new or enlarging T2 lesions at week 52 was reduced by $70 \%(p<0.0001)$ in the arm treated with the lowest dose of daclizumab and by $79 \%(p<$ 0.0001 ) in the $300 \mathrm{mg}$ group, comparing with placebo. The number of new or enlarged gadolinium-enhancing lesions at weeks 8 - 24 in the MRI sub-study $(n=309)$ was 4.8 in the placebo group, $1.5(-69 \% ; p<0.0001)$ in the arm receiving daclizumab $150 \mathrm{mg}$ and $1.0(-78 \% ; p<0.0001)$ in the group treated with the highest dose of the mAb. Regarding safety data, upper respiratory tract infections and pharyngitis were more common in daclizumab-treated patients, as well as cutaneous events (nevertheless, injection site reactions, erythema and induration were equally distributed in each group, affecting approximately $2 \%$ of the cases). A more than fivefold increase of liver enzymes (AST/ALT) was observed in $4 \%$ of daclizumab-treated patients and in less than $1 \%$ of those receiving placebo. ${ }^{37}$

After this 1-year period, an extension study was planned, which was called the SELECTION trial (Safety and Efficacy Extension Study of Daclizumab High Yield Process [DAC HYP] in Subjects With Multiple Sclerosis Who Have Completed Study 205MS201 [NCT00390221] to Treat Relapsing-Remitting Multiple Sclerosis, NCT00870740). This was also a 1-year, double-blind, randomised and controlled study with 517 patients who participated in the SELECT trial. The results were recently published ${ }^{38}$ and, basically, SELECT patients under treatment with daclizumab HYP 150 or $300 \mathrm{mg}$ were either randomised to a washout period of 24 weeks and then reinitiated on 
their original dose or stayed on the same dose for one year more, in a 1:1 proportion. Those previously receiving placebo either received daclizumab HYP 150 or $300 \mathrm{mg}$ again in a 1:1 proportion during one year. In these patients, the relapse rate at the end of the study was reduced by $59 \%$ $(p<0.001)$, with no discrimination between the two different doses of the mAb. The number of new or enlarging T2 lesions was 8.0 after the first year on placebo and switching to daclizumab in the SELECTION trial justified a reduction of $74 \%$ in this parameter $(p<0.0001)$. Also the number of gadolinium-enhancing lesions was reduced by $86 \%$ in patients receiving the $\mathrm{mAb}$ after 52 weeks on placebo $(p<$ $0.0001)$. In patients continuing on daclizumab, the relapse rate on the second year did not change compared with the first year under treatment and the reduction of new or enlarging T2 lesions was more evident in the second year for both the doses of the mAb. After a washout period of 24 weeks, it was not possible to identify any MRI rebound effect. The safety and tolerability issues were similar to those previously identified in the SELECT trial. ${ }^{38}$ However, one patient receiving daclizumab $300 \mathrm{mg}$ died from autoimmune hepatitis and in the previous SELECT study another patient died from a psoas abscess (in recovering from a cutaneous adverse event). These aspects have led to phase III studies to include a very strict liver function and skin monitoring.

In fact, the phase III program is currently ongoing and there are not yet results to report. It includes the DECIDE trial (Efficacy and Safety of Daclizumab High Yield Process Versus Interferon Beta-1a in Patients With RelapsingRemitting Multiple Sclerosis, NCT01064401), a 3-year study which compares subcutaneous daclizumab HYP $150 \mathrm{mg}$ once every four weeks with intramuscular interferon beta$1 \mathrm{a}$ as an active comparator. The primary endpoint will be the annualized relapse rate. EDSS progression and quality of life were defined as secondary objectives. This trial ended on March 2014 and patients are currently entering an extension phase, the EXTEND study (Long-Term Extension Study in Participants With Multiple Sclerosis Who Have Completed Study 205MS301 [NCT01064401] to Evaluate the Safety and Efficacy of BIIB019, NCT01797965), which is expected to be completed by December 2016 .

\section{Ocrelizumab and Ofatumumab}

There is long standing evidence that B cells play an important role in MS pathogenesis. ${ }^{39}$ The presence of oligoclonal bands and an increased lgG cerebrospinal fluid/serum-index provide evidence about the participation of components of the humoral immune system in the inflammatory events typical of MS and consist in two extremely relevant clinical tools currently used in practice. Such knowledge was used as rationale for a first attempt in using rituximab (MabThera ${ }^{\circledR} /$ Rituxan $^{\circledR}$; Roche Pharma and Genentech) for MS treatment. This chimeric B-cell depleting $\mathrm{mAb}$ (which binds specifically to the CD20 antigen) received its first approval in 1997 for the treatment of non-Hodgkin's lymphoma, but showed to be effective in patients with RRMS recruited into the small phase II HERMES trial (A Study to
Evaluate Rituximab in Adults With Relapsing Remitting Multiple Sclerosis, NCT00097188) $)^{40}$ and even showed some effect in patients diagnosed with primary progressive MS (PPMS) in the phase II/III OLYMPUS trial (A Study to Evaluate the Safety and Efficacy of Rituximab in Adults With Primary Progressive Multiple Sclerosis, NCT00087529). ${ }^{41}$ Rituximab set the basis for the development of newer anti-CD20 mAbs, which are currently being tested in MS therapeutics. The results obtained in phase II studies with the humanized ocrelizumab (Hoffman-La Roche and Genentech) and with the totally human ofatumumab (GlaxoSmithKline and Genmab) in RRMS patients are already published.

Ocrelizumab's safety and efficacy were evaluated in 220 RRMS patients in a 96-week, randomised, formally doubleblind, placebo-controlled phase II trial (NCT00676715). ${ }^{42}$ The main inclusion criteria were: to have at least two relapses within the previous three years with at least one in the previous year, an EDSS score between 1.0 and 6.0 and at least six T2 lesions on MRI and/or two relapses in the year before screening. Patients were randomized to receive intravenous placebo, intravenous ocrelizumab (600 $\mathrm{mg}$ or $2000 \mathrm{mg}$, administered with half the dose on day one and the other half on day 15) or intramuscular interferon beta-1a (30 $\mathrm{\mu g}$ per week), in a proportion of 1:1:1:1. After 24 weeks, those patients receiving placebo or interferon beta-1a were switched to ocrelizumab $600 \mathrm{mg}$, whereas those receiving the $\mathrm{mAb}$ continued treatment $(600 \mathrm{mg}$ or $1000 \mathrm{mg}$ only for patients treated with $2000 \mathrm{mg}$ in the first cycle of the trial). The total number of gadolinium-enhancing lesions over the weeks 12, 16, 20 and 24 versus placebo defined the primary endpoint and it was reduced by $89 \%$ $(p<0.0001)$ in the ocrelizumab $600 \mathrm{mg}$ group and by $96 \%$ $(p<0.0001)$ in the $2000 \mathrm{mg}$ arm. Both ocrelizumab doses also reached better outcomes than interferon beta-1a, while surprisingly the response to this last drug did not differ from the placebo. Among secondary clinical endpoints, the estimated annualized relapse rate was reduced by $80 \%$ $(p=0.0005)$ in patients receiving $600 \mathrm{mg}$ of the mAb and by $73 \%(p=0.0014)$ in those treated with the highest dose. After switching to ocrelizumab, those patients previously treated with placebo or interferon beta-1a reached similarly low disease activity. Considering safety issues, serious adverse events were reported in all the arms of the study. One woman treated with $2000 \mathrm{mg}$ of ocrelizumab died from disseminated intravascular coagulopathy, multiorganic dysfunction and pneumonia, but the relation of the study drug with this event remained uncertain. Nevertheless, the main adverse effects reported by patients were mild-tomoderate infusion-related reactions. Between 67 and $78 \%$ of patients (depending on the group they were previously included) completed a 144-week safety follow-up period. ${ }^{43}$ One patient died 19 months after last ocrelizumab infusion, but the reason was considered unknown. No opportunistic infections were detected after last dose administration and the majority of the patients were clinically stable, with no signs of disease activity even after B-cell repletion. 
The development of this mAb includes three phase III studies that are currently ongoing. There are two 96-week, randomized, double-blind, double-dummy, parallel-group studies to evaluate the efficacy and safety of intravenous ocrelizumab $600 \mathrm{mg}$ in comparison with subcutaneous interferon beta-1a (44 $\mu \mathrm{g}$ administered three times per week): the OPERA I and II studies (Studies of Ocrelizumab in Comparison With Interferon Beta-1a [Rebif $\left.{ }^{\circledR}\right]$ in Patients With Relapsing Multiple Sclerosis, NCT01247324 and NCT01412333). Each one of these trials included nearly 800 participants that are currently under regular follow-up. The primary outcome measure will be annualized relapse rate over 96 weeks and, among others, the secondary outcomes will include confirmed disability progression, proportion of relapse-free patients over trial duration and several MRI measures. There is also a third phase III, randomized, parallel-group, double-blind, placebo-controlled study to evaluate the efficacy and safety of intravenous ocrelizumab $600 \mathrm{mg}$ in adults diagnosed with PPMS: the ORATORIO study (A Study of Ocrelizumab in Patients With Primary Progressive Multiple Sclerosis, NCT01194570). This study enrolled 734 patients and the primary endpoint will be 12-week sustained EDSS progression up to 5.5 years. Secondary outcomes will include 24-week confirmed EDSS progression over up to 5.5 years, change in timed 25 -foot walk from baseline to week 120 , again several MRI measures, as well as safety and tolerability. The estimated primary completion dates of all these trials are October 2017 for the ORATORIO study, November 2019 for the OPERA I and January 2020 for the OPERA II.

Considering now ofatumumab, the results of a 24week, double-blind, randomised, placebo-controlled and dose-finding phase II trial (NCT00640328) were recently published. ${ }^{44}$ Thirty-eight individuals were enrolled, defining three sequential cohorts and receiving either intravenous ofatumumab $100 \mathrm{mg}(\mathrm{n}=8), 300 \mathrm{mg}(\mathrm{n}=11)$ or $700 \mathrm{mg}$ $(n=7)$. Each one of the groups included four placebotreated patients (12 in total). Several primary and secondary endpoints were defined, but the most relevant data are related with the fact that ofatumumab nearly completely suppressed the development of new gadolinium-enhancing lesions on monthly MRI scans in all the groups (the relative risk reduction versus placebo was estimated at $99.8 \%$; $p<0.0001$ ) and that peripheral B-cell depletion was observed with all the tested doses. ${ }^{44}$ Infusion-related reactions were frequent, but no unexpected safety issues appeared. There is another double-blind, placebocontrolled, parallel-group phase II trial currently ongoing: the MIRROR study (Ofatumumab Subcutaneous Administration in Subjects With Relapsing-Remitting Multiple Sclerosis, NCT01457924). It aims to investigate the safety and efficacy of a subcutaneous ofatumumab formulation (using increasing doses from $3 \mathrm{mg}$ up to $60 \mathrm{mg}$ against placebo) in 196 RRMS patients during 24 weeks. The primary outcome will be the number of new gadolinium-enhancing lesions in MRI scans at weeks 4,8 and 12 and the secondary objectives include a number of further MRI measures, safety, tolerability, pharmacokinetics, pharmacodynamics, dose-response relationship and several other clinical endpoints.

The trials with results already available demonstrate a very strong therapeutic effect of ocrelizumab and ofatumumab in RRMS patients, mainly in the reduction of MRI disease activity. They seem to be well tolerated, but the long-term effects of these anti-CD20 mAbs after several treatment cycles in MS patients over the years were not covered by all these mentioned early trials. To date, no PML cases have been reported after ocrelizumab administration and almost all the identified associated infections were resolved with appropriate therapy (as previously said, only one woman died with pneumonia and a systemic inflammatory syndrome). Also, anti-CD20 therapy has not been associated with an increased rate of cancer to date. Phase III trials will be crucial to establish the true potential of these drugs in MS therapeutics.

\section{GNbAC1 (anti-MSRV-ENV)}

GNbAC1 (GeNeuro Innovation SAS) is a humanized $\mathrm{mAb}$ directed against the MS-associated retrovirus (MSRV)ENV protein. A replication-competent MSRV, belonging to the HERV-W family of retroviruses was firstly described in $1997 .{ }^{45}$ Since then, research has been made on this field and it has been demonstrated that its presence is more frequent in MS patients than in controls. ${ }^{46}$ Further, a replicationincompetent member of the HERV-W family was also found to be associated with MS. ${ }^{47}$ So far, it is not entirely clear if the higher frequency of these retrovirus in MS patients has any pathogenic role or if it may only represent an irrelevant epiphenomenon.

Nevertheless, a first-in-human, double-blind, randomised, placebo-controlled, dose-ascending phase I trial was performed using GNbAC1 in 33 healthy male volunteers (First-in-Human Study With GNbAC1 in Healthy Volunteers, NCT01699555)..$^{48}$ Each one of the participants received a single intravenous infusion of the $\mathrm{mAb}$ at six different doses (from 0.0025 to $6 \mathrm{mg} / \mathrm{kg}$ ) or placebo. GNbAC1 was well tolerated and the maximum dose was reached without any serious adverse event (only minor and nonspecific complaints were recorded). This study set the basis for a phase II, randomised, placebo-controlled and dose-ascending safety and tolerability trial (Safety Study of GNbAC1 in Multiple Sclerosis Patients, NCT01639300) in $10 \mathrm{MS}$ patients. The final data collection date for primary outcome measure was April 2014 and, to date, there are no results available. A large phase II program is planned to follow, testing the efficacy and safety of GNbAC1 in MS patients.

\section{BIIB033 (anti-LINGO-1)}

Leucine-rich repeat and Ig domain containing NOGO receptor interacting protein 1 (LINGO-1) is a transmembrane receptor that is expressed on neurons and oligodendrocytes, which acts as an important negative regulator of myelination. ${ }^{49}$ Inhibition of LINGO-1 promotes 
oligodendroglial differentiation and myelination in vitro and in vivo, as well as remyelination in animal models of MS. ${ }^{50} \mathrm{~A}$ recent study described LINGO-1 as an important regulator of neural stem cell maturation to neurons in vitro ${ }^{51}$ and this relevance for cellular therapy is another aspect making this protein extremely attractive for future developments.

BIIB033 (Biogen) is a fully human anti-LINGO-1 mAb being developed for promoting neuroprotection and remyelination in patients with $\mathrm{MS}$. It was firstly tested in 64 healthy adult volunteers in a phase I, randomised and placebo-controlled trial. ${ }^{52}$ These subjects received intravenous infusions of single ascending doses of the $\mathrm{mAb}$ (from 0.1 to $100 \mathrm{mg} / \mathrm{kg}$ bodyweight). A second phase I study was designed to investigate multiple ascending doses of BlIB033 (from 0.3 to $100 \mathrm{mg} / \mathrm{kg}$ ) in 42 RRMS and SPMS patients (Safety Study of BIIB033 in Subjects With Multiple Sclerosis, NCT01244139). A comprehensive safety monitoring protocol was implemented during these trials and the $\mathrm{mAb}$ revealed to be well tolerated (no serious adverse events were recorded). ${ }^{52}$ As generally expected for a $\mathrm{mAb}$, its penetration into the CNS was low (the mean cerebrospinal fluid/serum ratio of BIIB033 was 0.06-0.09\%), but all the collected data encouraged further investigation of this remyelination-promoting agent in larger phase II studies.

The RENEW study (2150N201 BIIB033 In Acute Optic Neuritis, NCT01721161) is a phase II, randomised and placebo-controlled study that included 80 patients with a first episode of acute optic neuritis (it is expected that acute inflammation may contribute for the opening of the BBB, increasing CNS drug accessibility). Patients received a single BIIB033 dose of $100 \mathrm{mg} / \mathrm{kg}$ or placebo in a 1:1 ratio and the primary outcome was the change of p100 latency on visual evoked potentials at 24 weeks from the baseline of the unaffected fellow eye. Recruitment for this study ended in October 2014 and results are not yet available.

The SYNERGY study (Study to Assess the Efficacy, Safety, Tolerability, and Pharmacokinetics of BllB033 in Subjects With Relapsing Forms of Multiple Sclerosis When Used Concurrently With Avonex ${ }^{\circledR}$, NCT01864148) is also a phase II, randomised, double-blind, placebocontrolled, parallel-group, dose-ranging study in which patients diagnosed with RRMS and SPMS with relapses will be randomised to receive treatment with four different doses of intravenous BIIB033 (3, 10, 30 and $100 \mathrm{mg} / \mathrm{kg})$ in concomitance with intramuscular interferon beta-1a (30 $\mu \mathrm{g}$ once a week). The primary outcome will be the percentage of subjects experiencing a confirmed improvement of physical and/or cognitive function and/or disability over 72 weeks. Again, patients are currently being enrolled to the study and the final data collection date for primary outcome measure was defined as March 2016. Time will be needed in order to make the scientific community realize if this promising remyelinating and neuroprotecting $\mathrm{mAb}$ has really a clinically relevant impact.

\section{MOR103 (anti-GM-CSF)}

MOR103 (MorphoSys AG) is a fully human mAb directed against granulocyte-macrophage colonystimulating factor (GM-CSF). ${ }^{53}$ This molecule can act as a proinflammatory cytokine (stimulating activation, maturation and differentiation of macrophages, monocytes, neutrophils, eosinophils, dendritic cells and microglia) and has been demonstrated to be an attractive therapeutic target in various immune-mediated conditions, such as rheumatoid arthritis. ${ }^{54}$ In 96 patients diagnosed with this rheumatologic disease, a phase I/II randomised, placebo-controlled study was performed to evaluate safety and efficacy of multiple doses of MOR103 (0.3, 1.0 and $1.5 \mathrm{mg} / \mathrm{kg}$ bodyweight) over four weeks (Safety and Preliminary Efficacy of MOR103 in Patients With Active Rheumatoid Arthritis, NCT01023256). This drug demonstrated to have a good safety and tolerability profile and a rapidly measurable effect on variables related with disease activity over this short period of time..$^{55}$

This raised the interest in testing this antibody in different conditions and a randomised, double-blind, placebo-controlled phase $\mathrm{Ib}$ study to evaluate safety and pharmacokinetics of MOR103 in 30 patients with RRMS and SPMS was recently completed (Phase Ib Study to Evaluate MOR103 in Multiple Sclerosis, NCT01517282). Patients were randomised into three groups, receiving 6 intravenous infusions of MOR103 at three different doses $(0.5,1.0$ and $2.0 \mathrm{mg} / \mathrm{kg})$ or placebo. The primary completion date was January 2014, but the results are not yet published (however, in a press release by MorphoSys AG, positive results were announced in November 2014).

\section{MEDI-551 (anti-CD19)}

MEDI-551 (Medlmmune LLC) is a humanized $\mathrm{mAb}$ directed against CD19, which (similarly to CD20) is expressed on follicular dendritic cells and on B lymphocytes and their precursors. ${ }^{56}$ CD19 is also expressed on part of the plasma cells, which are the main responsible for the antibody production and, considering this, MEDI-551 is expected to have a broader B-cell-depleting activity than the mAbs targeting CD20.

A phase I/II adaptive design trial in patients with MS is currently ongoing (Safety and Tolerability Study of MEDI551, a B-cell Depleting Agent, to Treat Relapsing Forms of Multiple Sclerosis, NCT01585766). It is expected to include 512 subjects who will receive one of four subcutaneous or intravenous MEDI-551 dosages or placebo during phase I $(n=28)$ and one of six MEDI-551 dosages or intramuscular interferon beta-1a (30 $\mu \mathrm{g}$ per week) as an active com-parator in phase II. The primary outcome will be safety and tolerability over 169 days in phase I and proportion of relapse-free subjects over 337 days in phase II. The estimated primary completion date was January 2015 for the phase I study. The drug is also being tested in a number of phase I and II B-cell malignancy trials and in a phase I study in patients diagnosed with scleroderma. Time will be needed to understand this drug's potential in all these conditions and also its advantages and disadvantages regarding the anti-CD20 therapies. 


\section{CONCLUSION}

Natalizumab was the first mAb approved for MS treatment and, since its entrance in clinical practice, it has captured an important place in the therapeutic armamentarium over the last years. With the deepening of knowledge on the pathophysiology of the disease and the identification of new therapeutic targets, several mAbs have been identified as possible treatments to be used in MS patients, not only acting as anti-inflammatory agents, but also having potential as remyelinating, reparative and neuroprotective drugs. Most of these mAbs' clinical development programs are still in very early stages, but the future will certainly pass through the entrance of some of them (if not all) into our daily practice. Clinicians must therefore be aware of these advances. MS future therapeutic algorithms will certainly contain mAbs.

\section{REFERENCES}

1. Floss DM, Falkenburg D, Conrad U. Production of vaccines and therapeutic antibodies for veterinary applications in transgenic plants: an overview. Transgenic Res. 2007;16:315-32.

2. Kohler G, Milstein C. Continuous cultures of fused cells secreting antibody of predefined specificity. Nature. 1975;256:495-7.

3. Ffrench-Constant C. Pathogenesis of multiple sclerosis. Lancet. 1994;343:271-5.

4. Lobb RR, Hemler ME. The pathophysiologic role of alpha 4 integrins in vivo. J Clin Invest. 1994;94:1722-8.

5. Elices MJ, Osborn L, Takada Y, Crouse C, Luhowskyj S, Hemler ME et al. VCAM-1 on activated endothelium interacts with the leukocyte integrin VLA-4 at a site distinct from the VLA-4/fibronectin binding site. Cell. 1990;60:577-84.

6. European Medicines Agency. Tysabri (natalizumab): summary of product characteristics. [Consulted 2015 Mar 2]. Available from: http:// www.ema.europa.eu/docs/en_GB/document_library/EPAR_-_Product_ Information/human/000603/WC500044686.pdf.

7. Polman $\mathrm{CH}$, O'Connor PW, Havrdova E, Hutchinson M, Kappos L, Miller $\mathrm{DH}$, et al. A randomized, placebo-controlled trial of natalizumab for relapsing multiple sclerosis. N Engl J Med. 2006;354:899-910.

8. Rudick RA, Stuart WH, Calabresi PA, Confavreux C, Galetta SL, Radue $E W$, et al. Natalizumab plus interferon beta-1a for relapsing multiple sclerosis. N Engl J Med. 2006;354:911-23.

9. Tan CS, Koralnik IJ. Progressive multifocal leukoencephalopathy and other disorders caused by JC virus: clinical features and pathogenesis. Lancet Neurol. 2010;9:425-37.

10. Becher B. Central nervous system immune surveillance: on natalizumab, dendritic cells, and dangerous immune privilege. Arch Neurol. 2008;65:1566-7.

11. Barts and The London School of Medicine and Dentistry. Multiple sclerosis research: natalizumab PML update: Q4 2014. [Consulted 2015 Mar 3]. Available from: http://multiple-sclerosis-research.blogspot. com/2015/01/clinicspeak-natalizumab-pml-update-q4.html.

12. Plavina T, Subramanyam M, Bloomgren $G$, Richman $S$, Pace A, Lee $S$, et al. Anti-JC virus antibody levels in serum or plasma further define risk of natalizumab-associated progressive multifocal leukoencephalopathy. Ann Neurol. 2014;76:802-12.

13. Fernandez $O$. Best practice in the use of natalizumab in multiple sclerosis. Ther Adv Neurol Disord. 2013;6:69-79.

14. O'Connor PW, Goodman A, Kappos L, Lublin FD, Miller DH, Polman C, et al. Disease activity return during natalizumab treatment interruption in patients with multiple sclerosis. Neurology. 2011;76:1858-65.

15. Fox RJ, Cree BA, De Sèze J, Gold R, Hartung HP, Jeffery D, et al MS disease activity in RESTORE: A randomized 24-week natalizumab treatment interruption study. Neurology. 2014;82:1491-8.

16. Sempere AP, Martín-Medina P, Berenguer-Ruiz L, Pérez-Carmona N, Sanchez-Perez R, Polache-Vengud J, et al. Switching from natalizumab to fingolimod: an observational study. Acta Neurol Scand. 2013;128:e610.

17. Rinaldi F, Seppi D, Calabrese M, Perini P, Gallo P. Switching therapy from natalizumab to fingolimod in relapsing-remitting multiple sclerosis:

\section{CONFLICTS OF INTEREST}

The authors state no conflict of interests and have received no payment to perform this work.

\section{FUNDING SOURCES}

Filipe Palavra has received speaking honoraria and travel expenses for scientific meetings from Bayer HealthCare Pharmaceuticals, Biogen, Merck Serono, Novartis Farma and Teva Pharmaceuticals. His research has been supported by scientific grants received from Biogen, Merck Serono and from the Portuguese Foundation for Science and Technology (FCT).

clinical and magnetic resonance imaging findings. Mult Scler. 2012;18:1640-3.

18. Centonze D, Rossi S, Rinaldi F, Gallo P. Severe relapses under fingolimod treatment prescribed after natalizumab. Neurology. 2012;79:2004-5.

19. Bielekova B, Becker BL. Monoclonal antibodies in MS: mechanisms of action. Neurology. 2010;74:S31-40.

20. Coles AJ, Deans J, Compston A. Campath-1H treatment of multiple sclerosis: lessons from the bedside for the bench. Clin Neurol Neurosurg. 2004;106:270-4

21. Coles AJ, Wing MG, Molyneux P, Paolillo A, Davie CM, Hale G, et al. Monoclonal antibody treatment exposes three mechanisms underlying the clinical course of multiple sclerosis. Ann Neurol. 1999;46:296-304.

22. Paolillo A, Coles AJ, Molyneux PD, Gawne-Cain M, MacManus D, Barker GJ, et al. Quantitative MRI in patients with secondary progressive MS treated with monoclonal antibody Campath 1H. Neurology. 1999;53:751-

23. Coles AJ, Cox A, Le Page E, Jones J, Trip SA, Deans J, et al. The window of therapeutic opportunity in multiple sclerosis: evidence from monoclonal antibody therapy. J Neurol. 2006;253:98-108.

24. CAMMS223 Trial Investigators, Coles AJ, Compston DA, Selmaj KW, Lake SL, Moran S, et al. Alemtuzumab vs. interferon beta-1a in early multiple sclerosis. N Engl J Med. 2008;359:1786-1801.

25. Kurtzke JF. Rating neurologic impairment in multiple sclerosis: an expanded disability status scale (EDSS). Neurology. 1983;33:1444-52.

26. Cohen JA, Coles AJ, Arnold DL, Confavreux C, Fox EJ, Hartung HP et al. Alemtuzumab versus interferon beta $1 \mathrm{a}$ as first-line treatment for patients with relapsing-remitting multiple sclerosis: a randomised controlled phase 3 trial. Lancet. 2012;380:1819-28.

27. Coles AJ, Twyman CL, Arnold DL, Cohen JA, Confavreux C, Fox EJ et al. Alemtuzumab for patients with relapsing multiple sclerosis after disease-modifying therapy: a randomised controlled phase 3 trial. Lancet. 2012;380:1829-39.

28. European Medicines Agency. Lemtrada (alemtuzumab): summary of product characteristics. [Consulted 2015 Mar 3]. Available from: http:// www.ema.europa.eu/docs/en_GB/document_library/EPAR_-_Product_ Information/human/003718/WC500150521.pdf.

29. Jones JL, Phuah CL, Cox AL, Thompson SA, Ban M, Shawcross J, et al. IL-21 drives secondary autoimmunity in patients with multiple sclerosis following therapeutic lymphocyte depletion with alemtuzumab (Campath-1H). J Clin Invest. 2009;119:2052-61.

30. Nussenblatt RB, Thompson DJ, Li Z, Chan CC, Peterson JS, Robinson $\mathrm{RR}$, et al. Humanized anti-interleukin-2 (IL-2) receptor alpha therapy: long-term results in uveitis patients and preliminary safety and activity data for establishing parameters for subcutaneous administration. J Autoimmun. 2003;21:283-93.

31. Nussenblatt RB, Fortin E, Schiffman R, Rizzo L, Smith J, Van Veldhuisen $P$, et al. Treatment of non-infectious intermediate and posterior uveitis with the humanized anti-Tac mAb: a phase I/II clinical trial. Proc Natl Acad Sci USA. 1999;96:7462-6.

32. Bielekova B, Richert N, Howard T, Blevins G, Markovic-Plese S McCartin J, et al. Humanized anti-CD25 (daclizumab) inhibits disease 
activity in multiple sclerosis patients failing to respond to interferon beta. Proc Natl Acad Sci U S A. 2004;101:8705-8.

33. Bielekova B, Howard T, Packer AN, Richert N, Blevins G, Ohayon $\mathrm{J}$, et al. Effect of anti-CD25 antibody daclizumab in the inhibition of inflammation and stabilization of disease progression in multiple sclerosis. Arch Neurol. 2009;66:483-9.

34. Rose JW, Burns JB, Bjorklund J, Klein J, Watt HE, Carlson NG Daclizumab phase II trial in relapsing and remitting multiple sclerosis: MRI and clinical results. Neurology. 2007;69:785-9.

35. Rose JW, Watt HE, White AT, Carlson NG. Treatment of multiple sclerosis with an anti-interleukin-2 receptor monoclonal antibody. Ann Neurol. 2004;56:864-7.

36. Wynn D, Kaufman M, Montalban X, Vollmer T, Simon J, Elkins J, et al. Daclizumab in active relapsing multiple sclerosis (CHOICE study): a phase 2, randomised, double-blind, placebo-controlled, add-on trial with interferon beta. Lancet Neurol. 2010;9:381-90

37. Gold R, Giovannoni G, Selmaj K, Havrdova E, Montalban X, Radue $\mathrm{EW}$, et al. Daclizumab high-yield process in relapsing-remitting multiple sclerosis (SELECT): a double-blind, placebo-controlled trial. Lancet. 2013;381:2167-75

38. Giovannoni G, Gold R, Selmaj K, Havrdova E, Montalban X, Radue $\mathrm{EW}$, et al. Daclizumab high-yield process in relapsing-remitting multiple sclerosis (SELECTION): a multicentre, randomised, double-blind extension trial. Lancet Neurol. 2014;13:472-81.

39. Disanto G, Morahan JM, Barnett MH, Giovannoni G, Ramagopalan SV. The evidence for a role of B cells in multiple sclerosis. Neurology. 2012;78:823-32.

40. Hauser SL, Waubant E, Arnold DL, Vollmer T, Antel J, Fox RJ, et al. $\mathrm{B}$-cell depletion with rituximab in relapsing-remitting multiple sclerosis. N Engl J Med. 2008;358:676-88.

41. Hawker K, O'Connor P, Freedman MS, Calabresi PA, Antel J, Simon J, et al. Rituximab in patients with primary progressive multiple sclerosis: results of a randomized double-blind placebo-controlled multicenter trial. Ann Neurol. 2009;66:460-71.

42. Kappos L, Li D, Calabresi PA, O'Connor P, Bar-Or A, Barkhof $F$, et al. Ocrelizumab in relapsing-remitting multiple sclerosis: a phase 2, randomised, placebo-controlled, multicentre trial. Lancet. 2011;378:1779-87.

43. Kappos L, Calabresi P, O'Connor P, et al. Long-term safety and efficacy of ocrelizumab in patients with relapsing-remitting multiple sclerosis: week 144 results of a phase 2, randomised, multicentre trial. Presented at: $28^{\text {th }}$ Congress of the European Committee for Treatment and Research in Multiple Sclerosis. P362. Lyon, France, 10-13 October 2012.

44. Sorensen PS, Lisby S, Grove R, Derosier F, Shackelford S, Havrdova E, et al. Safety and efficacy of ofatumumab in relapsing-remitting multiple sclerosis: a phase 2 trial. Neurology. 2014;82:573-81.

45. Perron H, Garson JA, Bedin F, Beseme F, Paranhos-Baccala G, Komurian-Pradel $F$, et al. Molecular identification of a novel retrovirus repeatedly isolated from patients with multiple sclerosis. The Collaborative Research Group on Multiple Sclerosis. Proc Natl Acad Sci U S A. 1997;94:7583-8.

46. Ryan FP. Human endogenous retroviruses in multiple sclerosis: potential for a novel neuro-pharmacological research. Curr Neuropharmacol. 2011;9:360-9.

47. Antony JM, van Marle G, Opii W, Butterfield DA, Mallet F, Yong VW, et al. Human endogenous retrovirus glycoprotein-mediated induction of redox reactants causes oligodendrocyte death and demyelination. Nat Neurosci. 2004;7:1088-95.

48. Curtin $\mathrm{F}$, Lang $\mathrm{AB}$, Perron $\mathrm{H}$, Laumonier $\mathrm{M}$, Vidal $\mathrm{V}$, Porchet $\mathrm{HC}$, et al. GNbAC1, a humanized monoclonal antibody against the envelope protein of multiple sclerosis-associated endogenous retrovirus: a first-inhumans randomized clinical study. Clin Ther. 2012;34:2268-78.

49. Mi S, Miller RH, Lee X, Scott ML, Shulag-Morskaya S, Shao Z, et al. LINGO-1 negatively regulates myelination by oligodendrocytes. Nat Neurosci. 2005;8:745-51.

50. Mi S, Hu B, Hahm K, Luo Y, Kam Hui ES, Yuan Q, et al. LINGO-1 antagonist promotes spinal cord remyelination and axonal integrity in MOG-induced experimental autoimmune encephalomyelitis. Nat Med. 2007;13:1228-33.

51. Loov C, Fernqvist M, Walmsley A, Marklund N, Erlandsson A. Neutralization of LINGO-1 during in vitro differentiation of neural stem cells results in proliferation of immature neurons. PLoS One. 2012;7:e29771.

52. Tran J, Palaparthy R, Zhao J, et al. Safety, tolerability and pharmacokinetics of the anti-LINGO-1 monoclonal antibody BIIB033 in healthy volunteers and subjects with multiple sclerosis. Presented at $64^{\text {th }}$ American Academy of Neurology Annual Meeting. P02.021. New Orleans, LA, USA, 21-28 April 2012.

53. MorphoSys. MOR103. [Consulted 2015 Mar 4]. Available from: http:// www.morphosys.com/pipeline/proprietary-product-portfolio/mor103.

54. Hamilton JA. Colony-stimulating factors in inflammation and autoimmunity. Nat Rev Immunol. 2008;8:533-44.

55. Behrens F, Tak PP, Østergaard M, Stoilov R, Wiland P, Huizinga TW, et al. Mor103, a human monoclonal antibody to granulocyte-macrophage colony-stimulating factor, in the treatment of patients with moderate rheumatoid arthritis: results of a phase $\mathrm{lb} / \mathrm{lla}$ randomised, doubleblind, placebo-controlled, dose-escalation trial. Ann Rheum Dis. 2015;74:1058-64.

56. Tedder TF. CD19: a promising B cell target for rheumatoid arthritis. Nat Rev Rheumatol. 2009;5:572-7. 
Filipe PALAVRA

\section{Monoclonal Antibodies for Multiple Sclerosis Treatment}

Acta Med Port 2015:28:640-651

Publicado pela Acta Médica Portuguesa, a Revista Científica da Ordem dos Médicos

Av. Almirante Gago Coutinho, 151

1749-084 Lisboa, Portugal.

Tel: +351218428 215

E-mail: submissao@actamedicaportuguesa.com

www.actamedicaportuguesa.com

ISSN:0870-399X | e-ISSN: 1646-0758

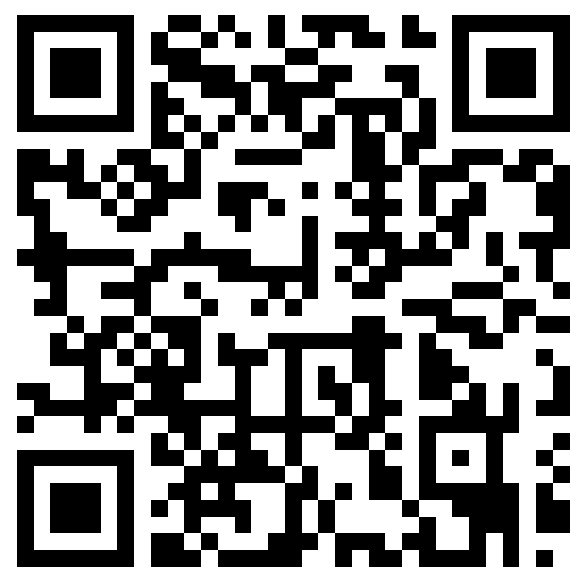

